\title{
Possible selves and self-esteem in uncertain times
}

\author{
Angeliki Leondari \\ Professor Emeritus \\ University of Thessaly. \\ Irinis 89, Agia Paraskevi 15342, Athens \\ Greece. \\ Vasilios Gialamas \\ Professor, National \& Kapodistrian \\ University of Athens. \\ 13a Navarinou, Athens 10680 \\ Greece \\ Marilena Giannakou \\ University of Thessaly. \\ Argonafton \& Filellinon, Volos 38221 \\ Greece.
}

\begin{abstract}
:
The present study aimed to investigate young people's possible selves in the context of a socio-economic crisis. Based on the idea that the formation of possible selves depends on the contextual characteristics of the immediate microsystem and the wider macrosystem, it was expected that the experience of uncertainty caused by the economic crisis would have an impact on their formation. The study also aimed to investigate whether self-esteem level and self-esteem stability correlate with the subjective probability of materializing one's hopes and fears, as well as with the elaborated notions of possible selves. Participants were 236 young adults, aged 18-35. The results show that the most salient hoped-for selves were related to career and health. High self-esteem participants were more likely to report specific possible selves, both hoped and feared. Similarly, participants with high self-esteem reported higher probability of realizing their hoped-for and avoiding their feared selves.
\end{abstract}

Keywords: Possible selves, hoped-for, feared selves, socio-economic uncertainty, self esteem level, self-esteem stability.

\section{Introduction}

Possible selves refer to future-oriented representations of the self. According to Markus and Nurius's (1986) classic approach, possible selves are defined as elements of the self-concept that 'can be viewed as a cognitive manifestation of enduring goals, aspirations, motives, fears and threats' (Markus and Nurius, 1986 p. 954). They include what one expects to become, hopes to become, as well as what one fears becoming. Therefore, possible selves include expected selves, hoped for selves and feared selves. Each one of these three may exist for any particular future domain, so that one can have many possible selves. Possible selves possess motivational and selfregulatory functions with three distinct components: valence (positive vs negative), elaboration (general vs specific), including prescriptive information and strategies for attaining positive or avoiding feared possible selves, and discrepancy between current and future selves (Oyserman \& Fryberg, 2006).

Possible selves are more likely to be effective in their self-regulatory function when they provide specific and detailed future images linked with strategies that connect current behaviours to future states (Markus \& Ruvolo, 1989; Oyserman, Bybee, \& Terry, 2006). People with highly developed possible selves, are more likely to set selfdefined, specific goals, plan strategies to realise them and tend to persist when confronted with difficulties than people with general, under-developed possible selves (Oyserman, Bybee, Terry, \& Hart-Johnson, 2004).

It has been proposed that the motivational value of possible selves is related to the estimated possibility of their attainment. That is, an individual is unlikely to engage is self-regulatory behavior for the attainment of a specific possible self if its realization does not seem possible or if the future seems completely uncertain. In other words, when a desired possible self is thought to be completely unachievable or the future seems uncontrollable, the motivational value of the possible self is very low (Dweck, 2000; Oyserman, 2009). 


\section{Possible selves and the socio-economic uncertainty}

The socio-economic context during which the present study took place, was a prolonged period of economic stagnation with youth unemployment as one of its principal problems. The study was conducted in Greece, during a severe and enduring economic recession. Its impact on the population, in terms of unemployment increase and reduced income, has mainly appeared after a number of austerity measures were implemented. The effects of these measures were especially felt by the age range 25-30, mainly through the reduced availability of job opportunities (Bell \& Blachflower, 2015).

An extensive body of literature suggests that youth unemployment is related to a decrease in physical and mental health and an increase in emotional and behavior problems (Bouras \& Lykouras, 2011; Fergusson, Horwood, \& Woodward, 2001). There is evidence that long periods of unemployment when the individual is young leave permanent scars, as the person starts to get isolated, to underestimate himself/herself, to be uninterested to the present and at the same time to feel depressed for the future. It follows that the way the individual visualizes his/her future and the formation of future goals is likely to be affected (Strandh, Winefield, Nilson \& Hammarstom, 2014). According to Hogg (2000), uncertainty is not an invariant property of the person, but of the immediate or more enduring social context in which people find themselves. Fundamental uncertainty is defined as a situation in which at least some essential information about future events cannot be known at the moment of decision either because this information does not exist or cannot be inferred from the existing data (Dequech, 1999). De Cremer and colleagues (De Cremer, Brebels \& Sedikides, 2008) refer to the sense of insecurity caused by the nature, structure and functioning of the socio- economic context as social uncertainty. While in a recent study, Smith and colleagues (Smith, James, Varnum, \& Oyserman, 2014) used the term 'world uncertainty', extending the original conceptual framework of this concept and linked it with individual's future goals. They define social uncertainty as 'the feeling that one may, or may not be able to achieve desirable outcomes, or avoid undesirable ones, because the path connecting means and ends is unpredictable and probabilistic, rather than clear and stable' (Smith et al., 2014, p.683).

Some research has associated individual cognitions that life is uncertain and the future unhopeful with problem or risky behaviours (Chung \& Elias, 1996; Hermans \& Dimaggion, 2007), and limited portrayals of future possibilities (Oyserman, 2009). According to Oyserman (2009), people are unlikely to engage in self-regulatory behaviour for the realisation of a possible self, if they feel that future goals cannot be attained despite high effort or that life is beyond their control.

\section{Possible selves and self-esteem}

Self-esteem refers to 'people's representations of their typical, or general global feelings of self-worth' (Kernis, 2005, p. 3). Possible selves relate to self-esteem in many different ways. An implicit assumption in many studies is that the primary motivation underlying the construction of possible selves is to protect or enhance self-esteem (Oyserman \& Fryberg, 2006). Thus, an important criterion for desiring or fearing a possible self is its potential to enhance or reduce self-esteem level (Leary \& Baumeister, 2000).

The existing body of research suggests that individuals with high self-esteem are more likely to produce successful future selves, whereas those with low self-esteem tend to envision unsuccessful selves. Research also shows that those who believe that positive selves are attainable have higher self-esteem than those who do not, and also they develop more strategies to attain their possible selves (Oyserman et al., 2004).

Self-esteem also seems to be positively correlated with occupational status (Kammeyer-Mueller, Judge \& Piccolo, 2008) and salary (Judge, Hurst, \& Simon, 2009), which are key indicators of an individual's socioeconomic status. Although few studies examined relations between self-esteem and occupational status or salary, research findings show that positive self-evaluations predict higher occupational status and salary (Judge et al., 2009), and generally positive career outcomes (Salmela-Aro and Nurmi, 2007).

It should be noted, however, that it is not only the level of self-esteem which is important (high /low), but also a second component, namely, stability (stable/unstable). Self-esteem stability is typically defined as within-person variability in self-esteem assessments (Kernis, 2005). It shows the extent to which individual's current feeling of self-worth exhibit fluctuations over a brief period of time (Foster, Kernis \& Goldman, 2007). It is distinct from selfesteem lability which focuses on fluctuations in self-esteem that occur in response to specific, immediate situational cues.

Unstable self-esteem individuals, compared to their stable self-esteem counterparts, have unclear self-concepts, show less determination in goal regulation (Kernis, Paradise, Whitaker, Wheatman, \& Goldman, 2000), focus on threatening aspects of unpleasant events, manifest a self-protective attitude toward learning, and overgeneralize the negative implications of domain specific failure (Waschull \& Kernis, 1996). In general, research shows that a higher degree of self-esteem stability is associated with better adjustment. 
In relation to expectations for the future, the combination of high, stable self-esteem might imply that attaining hoped-for and avoiding feared possible selves is within one's reach.

\section{The present study}

The first goal of the present study was to explore the range of possible selves (hoped and feared) in young people who have experienced the impact of a severe socio-economic crisis. We focused on young adults, aged 18-35, because this was the age range most affected by the unemployment prospect. We expected to find that the participants would emphasize mostly career and academic possible selves.

Additionally, we aimed to investigate whether there are differences between groups of respondents in relation to age and employment status and whether these differences are gendered. Our third goal was to investigate whether self-esteem level and self-esteem stability correlate positively with elaborated notions of possible selves, and also whether self-esteem level and stability correlate positively with the subjective probability of materializing one's hopes and goals. We hypothesized that individuals with higher and more stable self-esteem would be more likely to generate well elaborated, specific possible selves and would also envisage their possible selves as achievable compared to individuals with unstable self-esteem.

\section{Method}

\subsection{Participants}

In total 236 young people, aged 18-35 from all over Greece participated in the study. One hundred and sixty eight (71.2\%) were female and sixty eight $(28.8 \%)$ were male. Regarding employment status, $41.1 \%$ of the participants were students, $44.1 \%$ were employees and $14.8 \%$ were unemployed. Six percent had a high school qualification, $1.3 \%$ had technical qualifications, $61.3 \%$ had a university degree, and $31.4 \%$ had postgraduate qualifications. Ninety-three percent of the respondents were city residents.

The sample was divided in two age groups. The first included participants with age range 18-27( $\mathrm{n}=159,67.3 \%)$, and the second participants with age rand 28-35 $(\mathrm{n}=77,32.7 \%)$.

\subsection{Procedure}

The study involved the use of an on-line questionnaire. An invitation to participate in the study was posted through a website. Web links to the task were also circulated through student email lists and notice boards in a University campus of central Greece. Participants were asked if they would voluntarily consent to complete the questionnaire, insuring them of their anonymity and confidentiality of data and completed a consent page online. They were also presented with a brief explanation of the study. No incentives were provided. All respondent information was anonymous, and only a reference number and demographic information was used to identify respondents. The data from the responses to the questionnaires was sent to a database webpage that could be accessed only by the researchers.

\subsection{Measures}

Demographic information: The demographic information included participants' gender, age, place of residence, education and employment status (employed /unemployed/student).

Possible Selves: Participants filled out an open-ended questionnaire used by Oyserman and Markus (1990a, 1990b). They were asked to specify freely and rank their three most important hoped-for and feared selves that they currently imagined for themselves. For the purposes of the present study only the first most important hoped-for and feared self was used. Three aspects of possible selves were the focus of the present study, content, salience and elaboration. Salience refers to the extent to which the possible self is an active part of the person's mental life. Elaboration refers to the detail, vividness, and emotional depth of the possible self. In order to evaluate individuals' perceptions of the probability of realizing their possible selves, ratings of the perceived likelihood of possible selves were assessed using a 3 -point scale ( $1=$ not at all likely, $3=$ completely likely) with higher scores indicating higher degrees of likelihood.

The coding scheme for the content of possible selves was based on the well-established, reliable coding scheme developed by Oyserman and colleagues (Oyserman \& Markus, 1990a, 1990b). Six of the categories were based on the coding scheme mentioned above, while one new category was created by coders (social interest). Each hoped and feared self was coded into one of the following seven thematic content categories:(1) Education (e.g. finish my studies, obtain a post-graduate degree),(2) Career/occupation (e.g. find a job, fear to lose my job), (3) Interpersonal relationships (e.g. have many friends, get married, be a good mother), (4) Attainment of material goods (e.g. have a nice house, be able to travel abroad), (5) Health-related (e.g. be healthy, fear to be sick), (6) Intrapersonal (e.g. be happy, try to do my best),(7) Social interest (e.g. work for the community, participate in NGOs). 
Two individuals blind to the study hypotheses coded the response sets. They also rated the degree of elaboration of possible selves specifying it as specific or general. The inter-rater agreement averaged .92 .

However, as the percentage of responses generated by the category 'Social interest' was very small, a decision was made to omit this category from the analyses. We also decided to keep the health-related references as a separate category and not include them in the intrapersonal category as it was noticed that there was a substantial number of these references in relation to feared selves.

Self-esteem level: Self-esteem level was assessed with Rosenberg's Self-Esteem Scale (RSES, Rosenberg, 1965), a 10 item questionnaire that estimates global self esteem. It consists of items such as 'On the whole, I am satisfied with myself' and 'At times, I think I am no good at all'. Participants were instructed to complete the scale according to how they typically or generally feel about themselves. They responded to each item using a 5-point rating scale from 1(does not apply at all) to 5 (applies completely). Cronbach reliability coefficient for this study was $\mathrm{a}=.86$.

Self-esteem stability: We assessed perceived stability with the five-item Labile Self-Esteem Scale (LSES, Dykman, 1998), a unidimentional self-report scale. Some of the items include 'Compared to most people, my self-esteem changes rapidly', and 'My self-esteem shifts rapidly from feeling good about myself on one day to feeling bad about myself the next day'. Participants were asked to indicate their relative agreement with each item on a response scale from 1 (strongly disagree) to 5 (strongly agree) with higher scores indicating higher stability. Cronbach reliability coefficient for this study was a $=.89$.

\section{Results}

\subsection{Categories of possible selves}

Figure 1 shows the frequencies of the most salient hoped and feared possible selves in each of the six domains as reflected in the individuals' first response. Respondents generated more hoped-for possible selves pertained to career $(39,4 \%)$ than any other single category. The interpersonal relationships $(29.7 \%)$ and the intrapersonal issues $(13,6 \%)$ were the next most frequent, followed by education $(11,4 \%)$. The most commonly reported feared self pertained to health $(29,7 \%)$, followed by interpersonal relationships $(25.8 \%)$ and intrapersonal issues $(21,6 \%)$. Education was the least referred to feared self $(1,7 \%)$.

Figure 1. Frequencies (\%) of hoped-for and feared selves for each domain (whole sample)

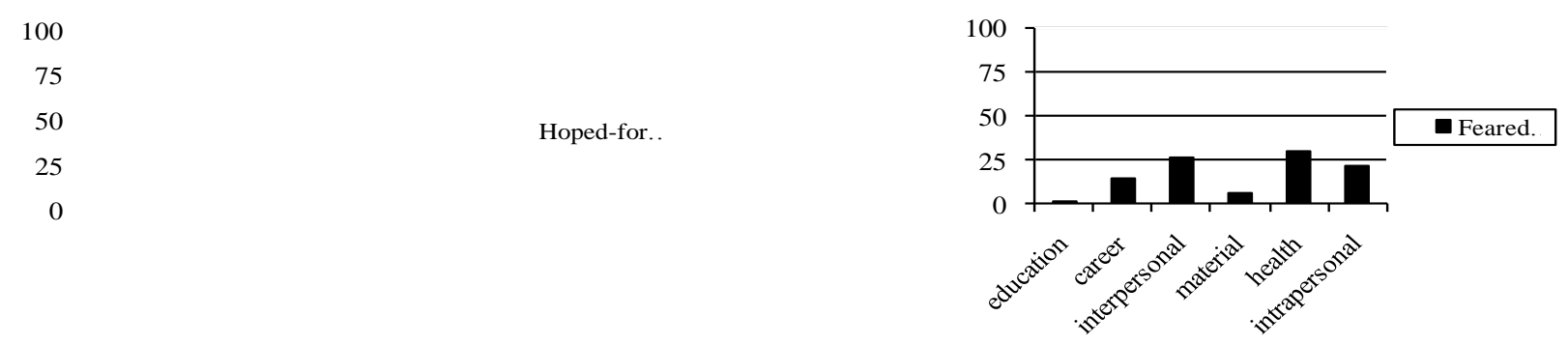

\subsection{Possible selves and demographic variables}

To examine differences in possible selves in relation to gender, age, and employment status, a series of chi-square analyses were carried out using adjusted standardized residuals. It should be noted that two of the six categories of hoped-for possible selves (material goods and health) and one category of feared selves (education) were not included in further analyses because fewer than $5 \%$ of the responses fell into each of those categories.

First, the relative frequencies of each hoped-for and feared possible self category were calculated separately for males and females, the two age groups and the three employment categories. There were no significant gender differences in relation both the hoped-for and feared selves, suggesting that males and females were conceptualizing their futures in relatively similar ways.

There were significant age differences as regards the hoped-for selves in relation to the categories of career/occupation and interpersonal relationships, $\chi 2(3)=29.75, \mathrm{p}<0.001$. Specifically, respondents in the age group 18-27 were more likely than the 28-35 group to report hoped-for selves in the domain of career/occupation (18-27: 51.3\%, 28-35: 21.4\%). 
Conversely, the 28-35 group was more likely that the 18-27 to report hoped selves in the domain of interpersonal relationships (18-27: 20.4\%, 28-35: 55.7\%). There were no significant differences as regards feared selves.

There were also significant differences in relation to employment status as regards the hoped-for selves, $\chi 2(6)=$ $24.81, \mathrm{p}<0.001$. Students were more likely than the other two groups (employees, unemployed) to report hoped-for possible selves in the domain of career/occupation (students: 56.5\%, employees: $30.9 \%$, unemployed: $33.3 \%$ ). On the other hand, both employees and the unemployed reported more hoped-for selves in the domain of interpersonal relationships (students: $16.3 \%$, employees: $46.4 \%$, unemployed: $30.3 \%$ ). There were no significant differences between the three groups as regards the feared selves.

\subsection{Possible selves and self-esteem}

The mean total score on global self-esteem scale was 36.45 ( $\mathrm{SD}=7.18$, men: $\mathrm{M}=36.84, \mathrm{SD}=7.2$, women: $\mathrm{M}=36.30, \mathrm{SD}=7.18$ ). There were no gender differences, but there were differences in relation to employment status and age group. A one-way analysis of variance (ANOVA) showed that the employees had a marginally significant higher self-esteem level than the students and the unemployed $\{F(2,233)=3.1, p=0.046\}$. Similarly, the 28-35 age group had significantly higher self-esteem than the 18-27 age group $\{\mathrm{F}(1,234)=10.03, \mathrm{p}=0.002\}$.

In relation to the degree of elaboration of possible selves, it was found that participants reported a greater proportion of specific hoped-for possible selves than general (specific: 59\%, general: $41 \%$ ), and also a greater proportion of specific feared selves (specific: $56 \%$, general: $44 \%$ ). However, this difference was significant only in the case of hoped-for selves $(\chi 2(1)=7.48, \mathrm{p}<0.006)$. There were no differences as regards gender, age or employment status in the degree of elaboration of possible selves, hoped-for or feared.

In relation to perceived likelihood of possible selves, participants as a whole reported a high probability of attaining their hoped-for possible selves (small: 9.7\%, medium: $38.1 \%$, high: $52.1 \%$ ) and a medium or high probability of avoiding their feared selves (small: 17.4, medium: 45.3, high: $37.3 \%$ ). Again there were no differences as regards gender, age or employment status.

In order to examine the relation between self-esteem level, self-esteem stability, the three demographic variables (gender, age, employment status) and the degree of elaboration of possible selves (general vs specific), a pair of logistic regression analyses were performed.

In relation to hoped-for possible selves, the Omnibus test of model coefficients showed no significant effects $\left(\chi^{2}=7.1, \mathrm{df}=6, \mathrm{p}=.311\right)$. However, a marginally non-significant positive effect $\left(\mathrm{B}=0.491, \chi^{2}=3.38, \mathrm{df}=1, \mathrm{p}=.066\right)$ was evident for self-esteem level. The higher the level of self-esteem, the greater the likelihood of referring to specific hoped-for possible selves. In relation to feared possible selves, the Omnibus test was significant $\left(\chi^{2}=15.1, \mathrm{df}=6\right.$ $\mathrm{p}=.019)$. The main predictor with significant coefficient at $\alpha=0.05$ was self-esteem level $\left(\mathrm{B}=0.885, \chi^{2}=10.0, \mathrm{df}=1\right.$, $\mathrm{p}=.002$ ). The higher the level of self-esteem, the greater the likelihood of referring to specific feared possible selves.

Stability of self-esteem had a significant negative coefficient $(B=-0.417, \chi 2=4.73, \mathrm{df}=1, \mathrm{p}=.030)$. Controlling for self-esteem level, the higher the stability of self-esteem the lower the likelihood of referring to specific selves. Gender showed a marginally non-significant effect $\left(B=-0.605, \chi^{2}=3.8, \mathrm{df}=1, \mathrm{p}=.051\right)$. The odds ratios indicated that women were less likely to report specific feared possible selves compared with men in the 28-35 age group.

Table 1. Logistic Regression Analysis of the degree of elaboration of possible selves (general/ specific)

\begin{tabular}{lrrrr}
\hline & \multicolumn{3}{c}{${\text { hoped }- \text { for }^{\mathrm{a}}}^{\mathrm{F}}$} & \multicolumn{2}{c}{ Feared $^{\mathrm{a}}$} \\
& $\mathrm{B}(\mathrm{SE})$ & $\begin{array}{l}\text { Exponent } \\
\text { coeff. }\end{array}$ & ofB(SE) & \multicolumn{2}{c}{$\begin{array}{l}\text { Exponent } \\
\text { coeff }\end{array}$} \\
\hline age 18-27 & $-0.43(0.34)$ & .649 & $-0.15(0.34)$ & .858 \\
S.E. level & $0.49(0.27)$ & 1.633 & $0.89(0.28)^{*}$ & 2.422 \\
S.E. stability & $-0.21(0.19)$ & .814 & $-0.42(0.19)^{*}$ & .659 \\
gender female & $0.00(0.30)$ & 1.001 & $-0.61(0.31)$ & .546 \\
employment & & & & \\
unemployed & $-0.33(0.42)$ & .717 & $0.30(0.43)$ & 1.355 \\
employed & $-0.06(0.34)$ & .938 & $0.10(0.34)$ & 1.106 \\
Constant & $-0.39(0.85)$ & .678 & $-1.18(0.86)$ & .307 \\
\hline
\end{tabular}

a. General $=0$, Specific $=1$

$$
* \mathrm{p}<0.05
$$

In order to investigate the relation of self-esteem level, self-esteem stability, the demographic variables (gender, age, employment status) and the probability of attainment of possible selves two ordinal regression analyses were performed, one for hoped-for and one for feared possible selves. 
In these models, degree of elaboration of possible self (general/ specific), age, gender, employment status, level of self-esteem, and stability of self-esteem were entered as predictors. One commonly used link function, cloglog link, was chosen to build the ordinal regression models (McCullagh, 1980).

In the ordinal regression probability of attainment of hoped-for possible self, the model assumption of parallel lines was not violated (chi-square values were not significant). The model with predictors provided a significantly better fit than the model which contained only the intercept $\left(\Delta(-2 \log\right.$ Likelihood $\left.)=\chi^{2}(7)=38.6, p<0.001\right)$. In addition, the result of Pearson's chi-square test indicated that the observed data were consistent with the estimated values in the fitted model $(\mathrm{p}>0.05)$. According to the Wald $\left(\chi^{2}\right)$ criterion (Table 2$)$, the probability of attainment of positive possible selves was predicted by self-esteem level only $\left(B=0.65, \chi^{2}=11.5, \mathrm{df}=1, \mathrm{p}=0.001\right)$. Participants with high self-esteem scores reported more frequently higher probability of hoped-for possible self attainment than those with lower self-esteem scores.

The results of the ordinal regression on the probability of attainment of feared possible selves were significant $\{\Delta(-$ 2logLikelihood $\left.)=\chi^{2}(7)=25.3, p=0.001\right\}$. The model assumption of parallel lines was not violated and the result of Pearson's chi-square test indicated an acceptable fit of the model $(\mathrm{p}>0.05)$. According to the Wald $\left(\chi^{2}\right)$ criterion (Table 2), the probability of avoiding the feared selves was predicted by self-esteem level $\left(\mathrm{B}=0.50, \chi^{2}=8.5, \mathrm{df}=1\right.$, $\mathrm{p}=0.003$ ) and employment status (unemployed - students $=-0.549, \chi^{2}=4.46, \mathrm{df}=1, \mathrm{p}=0.035$ ). Participants with high self-esteem scores reported more frequently higher probability of avoiding their feared selves than those with low self-esteem scores. Similarly, students reported more frequently higher probability of avoiding feared selves (45.4\%) than the unemployed (22.9\%) and the employees (34.6\%).

Table 2. Ordinal regression of the likelihood of hoped-for and feared possible selves

\begin{tabular}{lllr}
\hline & & hoped-for & \multicolumn{1}{l}{ feared } \\
& & B(SE) & B(SE) \\
\cline { 2 - 4 } Threshold & [Likelihood = 1.00] & $0.56(0.62)$ & $0.03(0.55)$ \\
& [Likelihood =2.00] & $2.53(0.61)^{*}$ & $1.76(0.55)^{*}$ \\
\hline & S.E. level & $0.65(0.19)^{*}$ & $0.50(0.17)^{*}$ \\
& S.E. stability & $0.21(0.13)$ & $0.06(0.12)$ \\
Independent & [general] & $-0.14(0.20)$ & $-0.06(0.18)$ \\
variables & [unemployed] & $-0.14(0.30)$ & $-0.55(0.26)^{*}$ \\
& [employed] & $-0.23(0.25)$ & $-0.35(0.22)$ \\
& [female] & $-0.09(0.22)$ & $-0.08(0.19)$ \\
& [age 18-27] & $0.35(0.25)$ & $0.12(0.21)$ \\
\hline & & &
\end{tabular}

\section{Discussion}

The present study aimed to contribute to an understanding of young people's possible selves within the context of a socio-economic crisis. We reasoned that as people have a fundamental need to feel certain about their world and their place in it, the psychological experience of the uncertainty created by the economic crisis, will influence their visions of the future. We also hypothesized that age and stage of development will have important implications for the impact of economic crisis.

We analyzed the content of participants' best possible self, that is, their most cherished future self. Consistent with our first hypothesis the participants of the present study generated more hoped-for selves in relation to the category career/occupation than in any other single category. This seems to reflect the widespread significance attached to career prospects and professional achievement. Interestingly enough this was not the case in relation to feared selves, where the category career/occupation ranked fourth with a proportion of $14.8 \%$. Although, we did not examine the relative prevalence of balance between hoped-for and feared selves, results would seem to imply a lack of balance. Given that as Oyserman and Markus (1990b) suggested, the ability to counter fears of future failure with detailed images of oneself reaching a desired end state leads to heightened motivation, the trend observed in the present study may signal a less intense motivational function of possible selves. On the other hand, it could also show an inclination toward positive self-relevant information, a finding documented in many previous studies (Rasmussen \& Berntsen, 2013; Taylor \& Brown, 1988).

Contrary to our expectations educational aspirations were not given a high priority among the young people of the present study in relation to hoped-for selves. The academic domain was even a less common focus in relation to feared selves. This was an unexpected finding, given that within the Greek context education is critical and great significance is accorded to academic accomplishments, while a substantial amount of family income is invested in the education of the children. 
On the other hand, Greece is the country with the highest rate of unemployed graduates among OECD countries, around 20\% in 2013 (Bell \& Blanchflower, 2015). One likely explanation would be that this result marks a mistrust in the education system and mirrors the complaint of industry and business representatives that the Education System fails to produce candidates that match the types of available jobs.

It could also mirror the fact that degrees and qualifications needed to acquire a particular job may have changed due to shifts in available employment opportunities, a fact which may force the young to re-examine previously formed educational aspirations. It is also possible that academic success becomes less salient at this stage of development, or that messages which promote other ideals or undervalue academics may be prevalent during this particular time period.

Health emerged as a salient domain of feared selves. The feared self mentioned most often was related to physical health. This finding may point to people's heightened susceptibility to the health risks of financial stress, and the fact that the crisis has undermined the social welfare and the public health care system in the country, with significant cuts in hospital budgets, understaffing, shortages of medical supplies, and long queues in overstretched hospitals.

We also found that participants showed a notable concern with interpersonal relationships and intrapersonal issues in relation both the hoped-for and feared selves. Men and women conceptualized their hopes and fears in relation to these issues in similar ways. Contrary to the existing research which documents that possible selves reflect genderstereotypic content (Anthis, Dunkel, \& Anderson, 2004; Brown, Diekman, 2010; Lips, 2004), gender differences were not significant in this study, a finding which is consistent with previous research with Greek samples (Leondari \& Gonida, 2008). Young women tended to focus on issues of career/occupation as much as men did. If this finding reflects a trend in the general population, it may show that young women are now more comfortable with explicit expressions of career ambitions and the importance of career-based pursuits. It is interesting to note that this is the case in a period during which female unemployment rates were significantly higher than those for males in the Greek labour market (Bell \& Blanch flower, 2015). It is also worth noting that young women focused on interpersonal issues as much as men did. This finding is in contrast with previous research which shows that women are still more likely than men to be concerned with the gender imperative to assume responsibility for relationships with others (Knox, Funk, Elliot, Bush, 2000).

Age differences generally mirrored the stage salient developmental tasks of the participants. The 18-27 age group reported more hoped-for possible selves in the domain of career/occupation, pointing out that leaving school to find employment is a central and difficult transition for young people. On the other hand, the older group reported more hoped-for possible selves in the domain of interpersonal relationships.

Participants as a whole reported a rather high self-esteem level. Past research has indicated high self-esteem individuals are better able to use information in a self-enhancing manner than low self-esteem individuals (Taylor \& Brown, 1988). High self-esteem level is thought to convey a certainty in one's abilities. In the context of the socio-economic uncertainty, certainty about the self is important for motivation. The difference in self-esteem level in relation to employment status reached significance only marginally, with employees scoring higher than the other two groups. It is noteworthy that the unemployed scored approximately at the same level as the other two groups. Turner (1995) argued that the 'implications of losing a job in an area with high unemployment rates and minimal reemployment opportunities are undoubtedly different from those involved with being jobless during a time in which opportunities for reemployment are plentiful' (p. 214). It might be that being unemployed during a period of high unemployment might buffer the negative consequences of unemployment as it is easier to attribute one's situation to external causes.

Participants reported a greater proportion of specific possible selves (hoped-for and feared) than general. This is an interesting finding given that the presence of well-elaborated possible selves is considered to contain prescriptive information which motivates individuals to move towards actualizing them (Markus \& Nurius, 1986; Markus \& Ruvolo, 1989; Oysterman, et al., 2004). Specifically research has shown that those with highly elaborated careerpossible selves are more motivated and goal-oriented and more likely, when confronted with threads, to persist with their goals.

Self-esteem level was significantly associated with the degree of elaboration of feared selves only. Respondents high in self-esteem were more likely to report specific feared selves than those with lower self-esteem. It seems that high self-esteem individuals tend to develop elaborated feared selves, which provide a clear goal to avoid. The potential self-regulatory impact of feared selves has been stressed by a number of different theories (Carver, 2004; Higgins \& Spiegel, 2004). Following these perspectives, youth with well elaborated feared selves would be expected to engage in self-regulatory behavior in order to avoid feared selves. Stability was negatively associated with the degree of elaboration of possible selves. Respondents with more stable self-esteem were less likely to report specific possible selves compared to those with unstable self-esteem. 
This result could imply that individuals with relatively more stable self-esteem tend to avoid focusing on the threatening aspects of unpleasant events and their negative implications. The subjective probability of attainment of possible selves, both hoped-for and feared, was predicted by self-esteem level only.

Respondents with high self-esteem scores reported more frequently higher probability of realizing their hoped-for and avoiding their feared selves than those with lower self-esteem. It could be that high self-esteem individuals feel more prepared to cause desired outcomes and avoid undesired ones. This is in line with previous research which indicates that individuals who believe that hoped-for possible selves are likely to be attained have higher selfesteem than those who do not (Oyserman et al., 2004).

\section{Limitations and future directions}

As with any research, the findings of the present study must be interpreted in light of the methodological constraints associated with data collection. The first concern is related to the use of a Web-based method. Several researchers (Buchanan, 2002; Pratelli \& Browne, 2002) identified a number of potential challenges to the reliability of online testing, such as lack of control in testing situation and the possibility of extraneous factors influencing responses.

Another concern refers to the fact that the sample drawn from an online population may be biased, as some studies show that those who participate in Web-based studies may be more intense internet users and have better internet skills than those who do not participate in such studies (Kehoe \& Pitkow, 1996). In addition, the present sample was clearly skewed toward the better educated.

Second, we hypothesized that as Greece's economic crisis has hit the younger generation hard, the participants of this study were facing an uncertain future and bleak career prospects. We did not specifically assessed participants' cognitions related to future uncertainty.

The categorization of respondents as employed/unemployed/economically inactive (students), probably covered important differences between them in terms of their employment status. A more refined categorization should make a distinction between full-time employment, part-time employment, as well as the duration of unemployment.

Finally, the present study had a cross-sectional design. As with any correlational study, determining the direction of causality is not possible. Future research should consider methods to examine the direction. Finally, because the focus of the present study was on the best possible self, the possibility of simultaneously pursuing multiple possible selves across a variety of domains was not taken into account.

\section{References}

Anthis, K. S., Dunkel, C. S., \& Anderson, B. (2004). Gender and identity status differences in late adolescents' possible selves. Journal of adolescence, 27(2), 147-52.

Bell, D., \& Blanchflower, D. (2015). Youth unemployment in Greece: measuring the challenge. IZA Journal of European Labor Studies, 4(1), 1-25.

Bouras, G., \& Lykouras, L. (2011). The economic crisis and its impact on mental health. Encephalos, 48, 54-61.

Brown, E. R., \& Diekman, A. B. (2010). What will I be? Exploring gender differences in near and distant possible selves. Sex Roles, 63, 568-79.

Buchanan, T. (2002). Online assessment: Desirable or dangerous? Professional Psychology: Research and Practice, 33(2), 148-154.

Carver, C. S. (2004). Self-regulation of action and affect. In R. F. Baumeister \& K. D. Vohs (Eds.), Handbook of self-regulation: Research, theory, and applications (pp.13-39). New York, NY: The Guilford Press.

Chung, H., \& Elias, M. (1996). Patterns of adolescent involvement in problem behaviors: Relationship to selfefficacy, social competence, and life events. American Journal of Community Psychology, 24, 771-784.

De Cremer, D., Brebels, L., Sedikides, C. (2008). Being uncertain about what? Procedural fairness effects as a function of general uncertainty and belongingness uncertainty. Journal of Experimental Social Psychology, $44,1520-1525$.

Dequech, D. (1999). Expectations and confidence under uncertainty. Journal of Post Keynesian Economics, 21(3), 415-430.

Dweck, C. S. (2000). Self theories: Their role in motivation, personality and development. Psychology Press.

Dykman, B. M. (1998). Integrating cognitive and motivational factors in depression: Initial tests of a foalorientation approach. Journal of Personality and Social Psychology, 74(1), 139-158.

Fergusson, D. M., Horwood, L. J., \& Woodward, L. J. (2001). Unemployment and psychosocial adjustment in young adults: Causation or selection?. Social Science \& Medicine, 53(3), 305-320.

Foster, J. D., Kernis, M. H., \& Goldman, B. M. (2007). Linking adult attachment to self-esteem stability. Self and Identity, 6, 64-73. 
Hermans, H. J. M., \& Dimaggio, G. (2007). Self, identity, and globalization in times of uncertainty: A dialogical analysis. Review of General Psychology, 11, 31-61.

Higgins, E. T., \& Spiegel, S. (2004). Promotion and prevention strategies for self-regulation: A motivated cognition perspective. In R. F. Baumeister \& K. D. Vohs (Eds.), Handbook of self-regulation: Research, theory, and applications (pp.171-187). New York, NY: The Guilford Press.

Hogg, M. A. (2000). Subjective uncertainty reduction through self-categorization: A motivational theory of social identity processes. European Review of Social Psychology, 11, 223-255.

Judge, T. A., Hurst, C., \& Simon, L. S. (2009). Does it pay to be smart, attractive, or confident (or all three)? Relationships among general mental ability, physical attractiveness, core self-evaluations, and income. Journal of Applied Psychology, 94, 742-755.

Kammeyer-Mueller, J. D., Judge, T. A., \& Piccolo, R. F. (2008). Self-esteem and extrinsic career status: Test of a dynamic model. Applied Psychology: An international review, 57, 204-224.

Kehoe, C., \& Pitkow, J. (1996). Surveying the territory: GVU's five WWW user surveys. The World Wide Web Journal, 1(3), 77-84.

Kernis, M. H. (2005). Measuring self-esteem in context: The importance of stability of self-esteem in psychological functioning. Journal of Personality, 73(6), 1-37.

Kernis, M. H., \& Paradise, A. W., Whitaker, D. J., Wheatman, S. R., \& Goldman, B. N. (2000). Master of one's psychological domain? Not likely if one's self- esteem is unstable. Personality and Social Psychology Bulletin, 26, 1297-1305.

Knox, M., Funk, J., Elliott, R., \& Bush, E. G. (2000). Gender differences in adolescents' possible selves. Youth and Society, 31(3), 287-309.

Leary, M. R., \& Baumeister, R. F. (2000). The nature and function of self-esteem: Sociometer theory. Advances in Experimental Social Psychology, 32, 1-62.

Leondari, A., \& Gonida, E. N. (2008). Adolescents' possible selves, achievement goal orientations, and academic achievement. Hellenic Journal of Psychology, 5, 179-198.

Lips, H. M. (2004). The gender gap in possible selves: Divergence of academic self-views among high school and university students. Sex Roles, 50(5-6), 357-371.

Markus, H., \& Nurius, P. (1986). Possible selves. American Psychologist, 41(9), 954-969.

Markus, H., \& Ruvolo, A. (1989). Possible selves: Personalized representations of goals. In L. A. Pervin (Ed.), Goal concepts in personality and social psychology (pp. 211-242). Hillsdale, NJ: Lawrence Erlbaum Associates.

McCullagh, P. (1980). Regression models for ordinal data. Journal of the Royal Statistical Society. Series B (Methodological), 42(2) (1980), 109-142.

Oyserman, D. (2009). Identity-based motivation and consumer behavior. Journal of Consumer Psychology, 19(3), 276-279.

Oyserman, D., \& Fryberg, S. (2006). The possible selves of diverse adolescents: content and function across gender, race and national origin. In C. Dunkel, \& J. Kerpelman (Eds.), Possible selves: Theory, research and applications (pp. 17-39). New York: Nova Science Publishers.

Oyserman, D., \& Markus, H. (1990a). Possible selves and delinquency. Journal of Personality and Social Psychology, 59(1), 112-125.

Oyserman, D., \& Markus, H. (1990b). Possible selves in balance: Implications for delinquency. Journal of Social Issues, 46(2), 141-157.

Oyserman, D., Bybee, D., \& Terry, K. (2006). Possible selves and academic outcomes: How and when possible selves impel action. Journal of Personality and Social Psychology, 91(1), 188-204.

Oyserman, D., Bybee, D., Terry, K., \& Hart-Johnson, T. (2004). Possible selves as roadmaps. Journal of Research in Personality, 38, 130-149.

Pratelli, M. E., \& Browne, B. L. (2002). Confirmatory factor analysis of Internet use and addiction. CyberPsychology and Behavior, 5(1), $53-64$.

Rasmussen, A. S., \& Berntsen, D. (2013). The reality of the past versus the ideality of the future: emotional valence and functional differences between past and future mental time travel. Memory \& Cognition, 41(2), 187200.

Rosenberg, M. (1965). Society and the adolescent self-image. Princeton, NJ: Princeton. University Press.

Salmela-Aro, K., \& Nurmi, J. E. (2007). Self-esteem during university studies predicts career characteristics 10 years later. Journal of Vocational Behavior, 70(3), 463-477.

Smith, G. C., James, L. E., Varnum, M. E. W., \& Oyserman, D. (2014). Give up or get going? Productive uncertainty in uncertain times. Self and Identity, 13(6), 681-700.

Strandh, M., Winefield, A., Nilsson, K., \& Hammarström, A. (2014). Unemployment and mental health scarring during the life course. European Journal of Public Health, 24(3), 440-445.

Taylor, S. E., \& Brown, J. D. (1988). Illusion and well-being: A social psychological perspective on mental health. Psychological Bulletin, 103(2), 193-210. 
Turner, J. B. (1995). Economic context and the health effects of unemployment. Journal of Health and Social Behavior, 36(3), 213-219.

Waschull, S. B., \& Kernis, M. H. (1996). Level and stability of self-esteem as predictors of children's intrinsic motivation and reasons for anger. Personality and Social Psychology Bulletin, 22, 4-13. 